\title{
REBELDIA VERTIGINOSA: AS PRIMEIRAS NARRATIVAS FICCIONAIS DE CARLOS DRUMMOND DE ANDRADE
}

\author{
Roberto Alexandre do Carmo Said \\ Doutor em Teoria da Literatura e Literatura comparada (UFMG) \\ Professor Associado de Teoria da Literatura (UFMG) \\ robertosaid@uol.com.br
}

\section{RESUMO}

Neste artigo, estudo a partir de uma pesquisa com fontes primárias e no âmbito da memória literária e cultural brasileira dois contos inéditos de Carlos Drummond de Andrade: "Rosarita" (1919) e "Joaquim do telhado" (1922). Com eles, pretendo analisar não apenas o período de formação intelectual e de experimentação estética e vivencial do jovem escritor em Belo Horizonte, primeira utopia urbanística da nação brasileira, mas o modo como ele interpela ficcionalmente, sob o prisma da capital mineira e das imagens de rebeldia e transgressão, os arranjos estéticos e políticos do tumultuado decênio de 1920 .

Palavras-chave: Carlos Drummond de Andrade; Ficção; Modernismo; Modernidade; Transgressão.

\section{RESUMÉ}

Cet article étudie, à partir d'une recherche avec des sources primaires et dans le cadre de la mémoire littéraire et culturelle brésilienne, deux nouvelles inédites de Carlos Drummond de Andrade, "Rosarita" (1919) et "Joaquim do telhado" (1922). La proposition est d'analyser non seulement la période de formation intellectuelle et expérimentation esthétique et expérientielle du jeune écrivain dans la ville de Belo Horizonte, la première utopie urbanistique de la nation brésilienne, mais surtout la façon dont il dialogue avec les arrangements esthétiques et politiques qui caractérisent la tumultueuse décennie de 1920, dans la perspective offerte par la capitale de Minas Gerais.

Mots-clés: Carlos Drummond de Andrade; fiction, modernisme, modernité, transgression.

Uma cena biográfica: após as sessões de cinema e as subsequentes noitadas divididas com os amigos nos bares ou nos cabarés da capital mineira, o jovem Drummond atravessava a pé o viaduto de Santa Tereza para chegar até à sua casa na Rua Silva Jardim, no bairro Floresta. Em algumas ocasiões, desviava-se do caminho habitual, trocando as calçadas pelos elevados e vertiginosos arcos de cimento que delineavam a forma do então monumental construto urbano. A trinta metros do chão, no alto do viaduto, 
sentava-se durante infinitos instantes para contemplar a cidade dormindo, antes de retomar sua caminhada.

Nos primeiros anos da década de 1920, o jovem Drummond podia ser visto cotidianamente caminhando pelas espaçosas ruas da capital mineira. Seu percurso, demarcado por poucos e repetidos pontos, girava em torno de um eixo virtual ancorado na Rua da Bahia, corredor central da cidade em cuja extensão se enfileiravam os locais privilegiados da boemia, da cultura e da política locais. Percorria-o com seu passo esquivo e desencontrado: as pernas leves e ligeiras, livres no novo território urbano, pareciam em desacordo com os braços sempre imóveis, pendidos paralelamente. O hábito de caminhar pelas ruas, transpondo longas extensões a pé, adquirido sob o estímulo do urbanismo belo-horizontino, tornou-se ao longo do século 20 uma das marcas registradas do poeta. $\mathrm{E}$ esse hábito não deve ser lido simplesmente como uma livre andança, despretensiosa, mas como uma espécie de viagem pedestre que o lançava, como um igual, por entre os iguais, nos espaços da cidade, permitindo-lhe vaguear e se imiscuir em sua comunidade. Como observa Jacques Rancière, a política republicana é a dos caminhantes. (RANCIÈRE, 1995.) Em suas andanças pelas ruas, avenidas e encruzilhadas do século, Drummond engendrara, como se atualizasse para sua condição local, o legado dos poetas românticos ingleses ou até, quem sabe, a flânerie baudelairiana, um modo próprio de atravessar o topos comunitário, isto é, um modo de ver a cidade (e seus habitantes) ao passar, de organizar os signos da paisagem urbana, com sua sucessão de quadros, com sua série de cenas que se abriam a sua vista como sketches de um filme. Em suas promenades, ele inventa um modo de ocupar e dar sentido à experiência sensível, oferecida pelo espetáculo urbano na cena periférica do capitalismo. 
Em seus anos de juventude, em Belo Horizonte, o jovem andarilho produziu um conjunto numeroso e heterogêneo de textos ramificados em diferentes gêneros literários: poemas em prosa e em verso, resenhas críticas, aforismos, contos e crônicas. Em sua maioria, esse material circulou em jornais e revista da época, mas permaneceu inédito em livro. Destaco desse conjunto, dois contos - gênero pouco frequentado pelo escritor ao longo de sua extensa trajetória literária - a fim de abordar criticamente as imagens de rebelde, anarquista, incendiário e futurista com as quais Drummond era visto e se apresentava em sua comunidade, nos tumultuados anos de crise da República e de emergência dos movimentos modernistas. Esses textos ensaiam um anseio de "libertação" estética e existencial e revelam os primeiros movimentos do jovem em busca de uma dicção autêntica e moderna.

Uma de suas primeiras narrativas ficcionais, "Rosarita" foi publicada em 1921 na revista da Faculdade de Medicina de Belo Horizonte, Radium. Nessa trama, o personagem Jayme de Castro, sujeito "amante dos paradoxos", revela a seus companheiros-ouvintes, entre eles o próprio narrador, em meio a tragos de absinto na mesa de um bordel, a história de Rosarita, proprietária do recinto, mulher poderosa e cobiçada na cidade. Ele a conhecia desde criança, quando ela chegara a sua casa com apenas doze anos, acompanhando a mãe que se empregava como doméstica. Era uma menina "fisicamente abjeta": "de olhos escaveirados, sorriso triste e boca sempre aberta", as "pernas cumpridas e escanzeladas", "escorria-Ihe catarro das narinas", além de ser "preguiçosa e desleixada", recorda Jayme.

A saga da garota iniciou-se no dia em que ela foi estuprada pelo "negrinho" Crispim, também criado da casa, nos fundos do quintal enquanto os patrões desfrutavam um feriado. 
Sem obter qualquer tipo de amparo ou de justiça pela violência sofrida, mãe e filha partiram, a fim de recomeçar a vida em outro canto. Encontraram abrigo em uma república de estudantes, onde a doméstica se arranjou como cozinheira. Passados alguns anos, a jovem Rosarita transformou-se, "como por milagre", tornou-se uma bela mulher, "uma primavera de carne floriu por entre os seus andrajos", porém em meio a uma vida desordenada, caiu na prostituição, após conhecer as sarjetas e as delegacias da cidade. Identificada com os "vícios" da nova atividade, praticados "com proficiência", subiu conquistando fortuna, embora fosse obrigada a dividi-la com o antigo algoz que, impune ao crime cometido, já não era mais o criadinho "ladrão de moedas", mas sim uma espécie de cafetão.

A breve narrativa, concisa e provocadora na mesma medida, reúne em seu enredo toda sorte de podridão e impostura social, trazendo à tona o que a sociedade local fingia não ver, revelando a hipocrisia e o falso moralismo reinantes na capital mineira. ${ }^{1}$ Ao tratar de negros no papel de estupradores, de empregadas pobres e sem direitos, "gente que se coiraça com um fatalismo consolante", neutralizando "as piores desgraças", ao abordar a impunidade, além de viciados em cocaína e absinto, o jovem contista cutucava com prazer e atrevimento as feridas de sua comunidade.

E o modo como o fazia torna-se ainda mais significativo se considerarmos que Crispim, nome do personagem canalha, estuprador e cafetão, será também o pseudônimo mais utilizado por Drummond durante os anos belo-horizontinos. Além de textos esparsos publicados no curso da década de 1920, Drummond assinará, entre 1930 e 1934, Antônio Crispim em uma série de crônicas publicadas na Imprensa Oficial de Minas Gerais. Com

\footnotetext{
${ }^{1}$ Ver o conto "Rosarita", Radium, Belo Horizonte, 1921. Pedro Nava relembra que, antes mesmo de ser apresentado pessoalmente a Drummond, já havia ficado profundamente impressionado com a ousadia desse texto. Cf. NAVA, 1978.
} 
efeito, a rebeldia transbordava para fora das margens da escrita. O tempo das primeiras experimentações literárias, das incansáveis leituras e do autodidatismo intelectual é também o tempo das arruaças do jovem inquieto e de seus comparsas, que se lançava em aventuras urbanas que envolviam o descarrilamento e a queima de bondes, as depredações dos jardins burgueses, as invasões de cemitérios, as barricadas nas portas dos cinemas em protesto contra os aumentos abusivos dos ingressos, as provocações e as debochadas vaias aos discursos dos políticos, assim como o acinte da vida boêmia e a quebra do (falso) decoro vigente. É o tempo da "mocidade solta", como relembra o próprio Drummond, tempo "dos arrancadores de placas de advogados e dentistas, / em noites de pouca ronda, / pequenos incendiários sem tutano, / de atear completas labaredas." (ANDRADE, 2002, p. 1139). Tempo em que o poeta invadia comícios oficiais "gritando em frente à sacada política do Grande Hotel / os morras que é de uso em comícios inflamados / antes que irrompa a cavalaria. Tempo em que ele desconsiderava o tempo da família mineira, com seus horários sagrados a regular o dia e a estabelecer o fluxo e a intensidade de movimento nas ruas belo-horizontinas. Tempo em que sua vida parecia pautar-se por uma franca atitude de desdém e zombaria às normas estabelecidas na cidade e na própria casa.

A vadiagem transgressora de Drummond, sua fase de vida mais rimbaudiana, inspirava-se nas páginas dos livros europeus que aportavam nos caixotes da Livraria Alves destino frequente das deambulações do jovem inquieto. Localizada na Rua da Bahia, a livraria alimentava-Ihe o espírito ávido pelas novidades importadas, que mais Ihe pareciam Nourritures terrestres. ${ }^{2}$ Conforme o lema moderno, a vida do rapaz desejava copiar os livros, sobretudo os franceses, que traçavam naquela época os paralelos e meridianos do mapa

\footnotetext{
${ }^{2}$ Título do livro de André Gide.
} 
artístico e cultural do planeta. Sua rebeldia crítica, revertida performática ou ficcionalmente em epopeia urbana, era assim matizada pelas lições tardias, assincrônicas, mas ainda eficazes da literatura vanguardista, conforme ele próprio sentencia, ao relembrar aqueles tempos: "Talvez influenciado pelo 'ato gratuito', de André Gide, eu me sentia impelido a esse tipo de ação, que pensando bem, nada tinha de gratuito. Seria a tentativa de resolver externamente contradições internas." (ANDRADE, 1987, p. 46)

Escritor, leitor, pseudônimo e personagens ficcionais alinhavam-se no desejo de se confrontar com a comunidade, de se opor a ela, de romper com os acordos tácitos de fingimento coletivo. Como se desejassem desconstruir a própria imagem que a cidade afirmava para si.

Em "Rosarita" não há, contudo, uma representação realista da sociedade belo-horizontina. Tampouco se encontra no texto a intenção de se demonizar a vida urbana moderna. Ao contrário, ambivalente por definição, a cidade será ao longo de toda a obra drummondiana objeto real e imaginário de amor e ódio. A dimensão mal e torpe do espaço urbano parece também ser desejado, tal como se configura em Baudelaire e em Dostoievski, como se a contradição fosse seu próprio estatuto, como se aí residisse seu encanto e sedução. Nesses termos, pode-se perceber o estranho prazer de Jayme de Castro, assim como a frieza do narrador, em relação à sordidez, às coisas corrompidas da coletividade urbana. A embriaguez desse personagem-testemunha da história de Rosarita aponta metonimicamente para a confusão de valores, para a deturpação dos sentidos presente no contexto referenciado na narrativa. 
De fato, o texto está diretamente ligado ao prazer de infringir o que se sabe proibido. Age "como um apanhado de folhas de urtiga, queimando e dando coceiras", nos dizeres de Pedro Nava, para quem a publicação assinalaria o início do modernismo em Minas Gerais, devido justamente a esse caráter desafiador. (NAVA, 1978, p. 63) Na visão do amigo e memorialista, os traços do modernismo se apresentam em Drummond, antes mesmo da Semana de 22, como uma espécie de afronta ao establisment social, como uma resposta ao atraso revestido de progresso, ao arcaico travestido de modernidade, que regia o imaginário belo-horizontino. O novo na escrita rebelde do jovem Drummond despontaria, conforme a lógica argumentativa de Nava, das próprias antinomias socioculturais de uma cidade moderna onde o footing domingueiro se caracterizava por segregar brancos e negros em diferentes calçadas da avenida central, nos primeiros anos de 1920.

A leitura de Nava, centrada no "conteúdo" e não na "forma" do conto drummondiano, angaria uma duradoura vertente interpretativa para o modernismo mineiro. Para ela converge, por exemplo, a posição de Laís Corrêa de Araújo, segundo a qual "a estrutura agrária decadente, a mentalidade conservadora e repressiva, apoiada num religiosismo estereotipado e deformante, possibilitaram, e exigiram mesmo, uma intervenção de reconhecimento e de denúncia" (ARAUJO, 2002, p. 183). Nessa perspectiva, seria o desejo de romper com a modernidade-perremista-mineira e seus padrões estéticos e culturais o elemento a desencadear o signo do jovem Drummond. Em Minas Gerais, ao contrário do que ocorria em São Paulo onde o modernismo teria se apresentado sob a égide ou a utopia de uma metrópole e de sua sociedade progressista, patrocinado pelo mecenato de uma elite ilustrada, não obstante as contradições ali existentes, o movimento belo-horizontino seria o resultado de uma indisposição, isto é, de uma negação do status quo. A formação discursiva, 
no sentido focaultiano do termo, na qual estavam inseridos os modernistas mineiros não os induzia senão à afronta e à crítica do estabelecido.

Pode-se também ver a ação desses signos de rebeldia e provocação em "Joaquim do telhado", narrativa com a qual o jovem escritor itabirano venceu o Concurso da Novela Mineira em 1922, obtendo a premiação de cinquenta mil réis. Nesse texto narrado em 3a pessoa, o protagonista, Joaquim da Silva, sapateiro, até então, reconhecido e respeitado, passou a sofrer com a hostilidade de toda a cidade, após adquirir o hábito de subir até o telhado de sua casa, a fim de filosofar sobre as coisas da vida, repassando as leituras com as quais ocupava seu tempo. Movido pelo "imenso desejo de aprender coisas novas", de "ter uma ideia mais vasta do mundo", resolveu contemplá-lo das alturas, já que não mais "havia lugares desconhecidos", conforme se justifica ao irmão, que foi convocado para trazê-lo de volta à realidade:

\footnotetext{
Lá de cima, eu estaria num nível superior ao desses pobres diabos de juízo: um horizonte mais amplo, ideias mais claras... A ânsia que eu tinha de utilizar o cérebro! Pois subi! E gostei. E continuei. O que se vê, o que se contempla dum telhado! (ANDRADE, 1939)
}

Sua ânsia de conhecimento e o comportamento inusitado lhe renderam, todavia, enormes problemas. Embora fosse "um homem normal", cujo "cérebro regulasse perfeitamente" atos "ordenados, arrumados e lógicos", embora fizesse "sapatos, com proficiência e honestidade" durante o dia, "não havia quem não o chamasse de doido." Tornou-se, assim, alvo de chacota da criançada e objeto da ira e da desconfiança de seus concidadãos. Perdeu a noiva, Ludovina, e as antigas amizades, sendo doravante tratado cruelmente como louco. 
Joaquim parece filiar-se a uma linhagem de personagens literários - entre os quais Bartleby tornou-se atualmente o mais conhecido - movidos pela "potência-do-não". Tal como o copista magro e lívido criado por Melville, cuja fórmula I would prefer not to "enlouquece todo o mundo", Joaquim interrompe repentinamente suas atividades (DELEUZE 1997, p. 80). Sua recusa do mundo do trabalho, seu abandono da technai, apresenta-se como a liberação de uma potência a qual Aristóteles nomeava hexis. Não se trata de uma potência entendida como potencial genérico, uma habilidade latente que poderá ser desenvolvida futuramente pelo sujeito, mas a potência de quem já domina uma arte ou um saber e que pode ou não os colocar em exercício. A hexis se define exatamente pela possibilidade de não ser colocada em ato, pela sua não-realização, como esclarece Giorgio Agamben (2018, p. 63). Como bom e reconhecido sapateiro, Joaquim decide suspender (literalmente) seu labor e dedicar-se à contemplação. Sua "inoperosidade" no alto do telhado o libera de qualquer destino ou tarefa pré-determinada socialmente e o lança em uma zona de indeterminação, em uma condição de arte, isto é, o habilita para a arte.

Se, como sugere Deleuze, o ato de criação é um ato de resistência, as primeiras narrativas ficcionais do jovem Drummond revelam uma complexa potência transgressora. Enquanto o escritor exercita experimentalmente sua escrita e, desse modo, provoca e descortina a hipocrisia de sua cidade, onde tão bem se enfeixam os signos urbanísticos, sociais e políticos da moribunda República nacional, Joaquim, seu personagem, resiste à ação, suspende seu exercício, desafiando seu meio pela potência perturbadora da hexis.

Essas primeiras narrativas ficcionais drummondianas, gênero ao qual o escritor pouco se dedicou posteriormente, fundamentam-se e interseccionam-se no tom crítico, na acidez 
que destilam sobre a comunidade de leitores mineiros, indiretamente representada e interpolada em ambas estruturas ficcionais. O desconforto causado por seus textos iria repercutir na cidade, a ponto de Ihe impingir uma aura demoníaca e de lhe inserir no distinto e temido grupo dos discípulos de Oscar Wilde, tal como se revela no retrato delineado por Lincoln de Souza, um dos companheiros do poeta na ocasião:

Quem pretender fazer psicologia d'aprés les masques, erra. E erra grosseiramente. Vejam vocês aí esse menino Carlos - esguio, pálido, seráfico, um sorriso tímido de criança; um perfil suave, que se veste dandinescamente pelo Aquino; que toma sorvete no Estrela - é uma alma perversíssima de Satan! (SOUZA, 1921)

Entretanto, deve-se notar que, se os textos apresentam um teor corrosivo, se realmente dão coceira como sugere Pedro Nava, se, de fato, opõem-se à ordem vigente, revelando a alma perversa de quem os escreveu, não é exatamente porque criticam o modelo político ou o econômico adotados. A dimensão negativa que atravessa as páginas do jovem escritor não se refere às formas propriamente políticas, isto é, às formas representativas de dominação estatal, não se volta ao partido soberano, a seus mecanismos violentos e corruptos de perpetuação, nem tampouco à estrutura econômica perversa daí decorrente.

A inteligibilidade do confronto anunciado passa por outras vias, mais abstratas, mas também mais profundas. Ao se voltar ao elemento banal de todos os dias, dando visibilidade às microtexturas morais, às relações capilares de força que, disseminadas, ou melhor, escamoteadas por entre as práticas do cotidiano, compõem a trama da vida social, as narrativas realizam uma espécie de esquadrinhamento disciplinar da sociedade belo-horizontina. Como se denunciassem, em dicção irônica e alegórica, o processo de 
normalização que atravessa e constitui o corpo social da capital republicana, o regime de verdades que o fundamenta.

As trajetórias de Rosarita e de Joaquim, microepopeias urbanas, apontam, ainda que sob diferentes perspectivas de sentido, para o desejo de um desvio necessário, para o desejo de suspender a modernidade vigiada e truculenta efetivada na cidade-luz das Minas Gerais, a fim de furá-la, em um golpe de escrita, abrindo seus horizontes para um novo tempo. Tanto um quanto outro personagem são efeitos e, ao mesmo tempo, distorções dos poderes que regem os discursos sociais na cena local. ${ }^{3}$

Como formula Barthes, o conjunto de leituras de um escritor não constitui necessariamente sua memória, mas sim o seu sintoma (BARTHES, 2003). Nesses termos, pode-se dizer que a relação tempestuosa do jovem escritor ainda "sem profissão" que vivia de benevolente mesada paterna com seu meio manifestava-se tanto sobre as superfícies de papel quanto sobre as de concreto da capital. Seu corpo duplicava-se em um e em outro espaço de inscrição, lançando-se nas ruas e nas páginas de jornais e revistas da cidade a um só tempo moderna e provinciana. Vida e texto pareciam embaralhados na busca de um modo de existência, pois como define Deleuze, "um estilo é sempre também um estilo de vida, de nenhum modo algo pessoal, mas a invenção de uma possibilidade de vida." (DELEUZE, 1998, p. 126)

As aventuras drummondianas, que reencenavam de modo oblíquo o impulso transformador das vanguardas europeias, seriam igualmente reencenadas mais tarde pelas

\footnotetext{
${ }^{3}$ Não deixa de ser curioso que $O$ gerente, umas das raras incursões futuras de Drummond no campo da narrativa ficcional, seja regido por essa mesma política de escrita, voltada às máquinas de poder social, apresentando-nos um sujeito que comia os dedos das senhoras da alta sociedade carioca, a qual o personagem frequentava com destaque e honradez.
} 
futuras gerações de escritores mineiros. A começar pela escalada pelos arcos do viaduto de Santa Tereza, que foi consagrado como seu gesto maior de transgressão comportamental, a ponto de se transformar em uma espécie de rito de libertação para os futuros rapazes, que inconformados com os limites impostos pela Serra do Curral, também desejaram se mudar para o alto de um telhado. Não foram poucos os que repetiram ou ensaiaram a vertiginosa subida, glosando o ato do poeta, o qual impossibilitado de flanar, como nas metrópoles, inventava uma deambulação singular, desguiando-se para o topo do viaduto - ou de um telhado. ${ }^{4}$ Como se de lá do alto, seus seguidores pudessem acessar simbolicamente uma outra cidade, a civilitas cultural e poética inventada pelo escritor por cima da urbs dos coronéis, políticos e burocratas da República.

Nesse sentido, é interessante observar o deslocamento provocado pelo modernismo brasileiro nos jogos de força e de influência literárias atuantes na formação dos novos escritores, pois com a consolidação do movimento, alguns escritores nacionais e, em particular medida, Drummond, ocuparão doravante parte do lugar referencial, antes preenchido exclusivamente pelos artistas estrangeiros. No contexto local, então, a presença do poeta será avassaladora. Toda uma linhagem de artistas e intelectuais mineiros se formará seguindo seu rastro - sua vertiginosa flânerie.

Os atos de insubordinação perpetrados pelo jovem itabirano não devem, como argumentei, ser considerados gratuitos. Ao contrário, inscritos na atmosfera política e

\footnotetext{
4 "A escalada ao viaduto tornou-se com o tempo um rito da memória das gerações posteriores a de Drummond. A geração dos 40 , formada pelo quarteto dos vintanistas, retomavam o gesto do poeta de Itabira. 0 mesmo se dará com a geração suplemento, nos anos 60 . A repetição passa a ter significados simbólicos. Ao contrário do que contabiliza Nava, o viaduto tem cerca de dezessete metros, o que equivale a um edifício de 6 andares. Apenas a geração do Edifício não escalou. Segundo Werneck, há uma frase da personagem principal do romance de estréia de Autran Dourado, 'Coragem besta eu não tenho'. A coragem deles foi canalizada para as pichações e para as publicações distribuídas clandestinamente." WERNECK, 1992.
} 
cultural da capital, eles expressavam, para além do desejo juvenil de desordem, uma postura crítica, uma latência questionadora desejando romper, ou quem sabe suspender, as bordas daquele mundo simbolicamente definido pela avenida perimetral da cidade. As provocações "daqueles rapazes de belo horizonte" revelavam certa conotação política apresentando-se, conforme observa Nava, "como reação legítima à hostilidade de um ambiente moldado sob as leis da família mineira e do poder hipócrita do PRM" (NAVA, 1978, p. 182). Tratava-se de uma atitude aberta e acintosa de desrespeito ao consentido, ao automatismo dos hábitos, ao conformismo conveniente aos arranjos culturais e políticos do local.

Nesse sentido, a conduta incendiária e anarquista do jovem Drummond era também uma forma de questionar as práticas sociais corriqueiras, de se indispor com a fantasiosa belle-époque belo-horizontina, em sua pretensão de modernidade e cosmopolitismo, simulados não apenas no traçado urbano, mas também na cópia de hábitos e comportamentos europeus, a partir dos quais a aristocracia aburguesada da cidade imaginava assegurar seu pertencimento à mais nobre civilização ocidental. Sua rebeldia, refabulada para a escrita, criticava ainda a artificialidade dos padrões artísticos hegemônicos que, sob o fascínio da tradição clássica, propagavam uma cultura ornamental e ostentatória, devota do beletrismo como forma de elegância e distinção social. Rebeldia, vida e literatura entrelaçavam-se nos passos esquivos do jovem Carlos.

\section{REFERÊNCIAS}

AGAMBEN, Giorgio. O que é o ato de criação? In: $O$ fogo e o relato: ensaios sobre criação, escrita, arte e livros. São Paulo: Boitempo, 2018. p.59-81.

ANDRADE, Carlos Drummond de. Rosarita, Radium, Belo Horizonte, 1921. Coleção Linhares, Biblioteca Central, UFMG. 
ANDRADE, Carlos Drummond de. Joaquim do telhado. Belo Horizonte, Folha de Minas, 26 de fevereiro de 1939.

ANDRADE, Carlos Drummond de. Tempo vida poesia; confissões no rádio. Rio de Janeiro: Record, 1987.

ANDRADE, Carlos Drummond de. Poesia completa. Conforme as disposições do autor. Rio de Janeiro, Nova Aguilar, 2002.

ARAÚJO, L. C. de. A poesia modernista de Minas. In: ÁVILA, Affonso (Org.). O Modernismo. São Paulo: Perspectiva, 2002. p. 179 -192.

BARBOSA, João Alexandre. "Drummond e a poesia como conhecimento". In: WALTY, Ivete Lara, CURY, Maria Zilda. Drummond: poesia e experiência. Belo Horizonte: Autêntica, 2002. p.45-60.

BARTHES, Roland. Roland Barthes por Roland Barhes. São Paulo: Estação Liberdade, 2003.

BUENO, Antônio Sérgio. O modernismo em Belo Horizonte: década de vinte. Belo Horizonte: Ed. UFMG, Proed, 1982.

CANÇADO, José Maria. Os Sapatos de Orfeu. Biografia de Carlos Drummond de Andrade. São Paulo: Página Aberta, 1993.

DELEUZE, Gilles. Crítica e Clínica. São Paulo: Editora 34, 1997.

DELEUZE, Gilles. Conversações. São Paulo: Editora 34, 1998.

GLEDSON, John. Poesia e poética de Carlos Drummond de Andrade. São Paulo: Duas cidades, 1981.

NAVA, Pedro. Beira-mar. Rio de Janeiro: José Olympio, 1978.

RANCIÈRE, Jacques. Políticas da escrita. Rio de Janeiro: Editora. 34, 1995.

SANTIAGO, Silviano. Ora (direis) puxar conversa! Ensaios literários. Belo Horizonte, Ed. UFMG, 2006.

SOUZA, Lincoln de. Os discípulos de Wilde, Diário de Minas, 08 jan. 1921.

WERNECK, Humberto. $O$ desatino da rapaziada: jornalistas e escritores em Minas Gerais. São Paulo: Companhia das Letras, 1992. 